\title{
The impact of the use of health information and communication technology on health care delivery in Manitoba, Canada
}

\author{
I srael R Kabashiki ${ }^{1}$, Ngozi I Moneke ${ }^{2}$
}

1. IZ New Consulting, Winnipeg, Manitoba, Canada. 2. Allabouthealth, Inc, Freeport, New York 11520, United States.

Correspondence: Israel R. Kabashiki. Address: 200-5 Donald Street, Winnipeg, Manitoba, Canada, R3L 2T4. E-mail: Consulting@izglobalexpertise.com

Received: J une 4, 2014

DOI : $10.5430 /$ jha.v3n6p8
Accepted: August 20, 2014

URL: http://dx.doi.org/10.5430/jha.v3n6p8

\section{Abstract}

Background: Health Information and Communication Technology (HICT) has the potential to reduce patient wait time and improves patient satisfaction. The Long wait times for patients to receive medical services are a big issue in Canada. The Canadian government has invested in Information and Communication Technology (ICT) to shorten patient referral wait times for medical services. Little was known about the association between ICT investments and the quality of health care delivery, and particularly between the use of ICT and referral wait times in the Manitoba Health System (MHS).

Methods: The purpose of this quantitative correlational study was to determine if a relationship existed between the use of HICT and the quality of health care delivery in the MHS. The quality of health care delivery was measured in terms of referral wait time, health information sharing effectiveness, physicians' satisfaction, and patients' satisfaction.

Conclusion: Findings indicated the absence of a significant association between HICT use and referral wait times. Significant correlations were found to exist between (1) HICT use and health information sharing effectiveness, (2) HICT use and physician's satisfaction, and (3) HICT use and patient's satisfaction. Four recommendations emerged from this study: First, patient satisfaction should be used as an indicator of the quality of health care delivery. Second, health knowledge repository and expert systems should be integrated into health ICT systems to minimize unnecessary referrals. Third, a mixed health system should be implemented to shorten wait times. Fourth, the portability of the Canadian Medicare should be enhanced to allow Manitobans in particular and Canadians in general to seek medical services abroad. This study was intended to contribute to the existing body of knowledge associated with ICT investments' outcomes and health care delivery in the MHS.

\section{Key words}

Information technology, Wait times, Patient satisfaction, Physician satisfaction

\section{Introduction}

Health Information and Communication Technology (HICT) has the potential to improve the efficiency and effectiveness of health care as well as the quality of care and patient safety ${ }^{[1]}$. For the purpose of this study HICT comprises electronic medical records, electronic health records, personal health records, health knowledge repository, and expert 
systems. The introduction of the Canadian universal health insurance system ${ }^{[2]}$, also known as Medicare ${ }^{[3]}$, in 1966, has altered the way medicine is practiced in Canada. Since, the range of services and nature of treatment options have changed significantly ${ }^{[4]}$. The Canadian Healthcare System (CHS) has been seeking effective ways to respond to new challenges such as long wait for medical services, shortage of healthcare providers, an aging population that requires special care, and the rising cost of health care. These factors contribute to the decline of the quality of medical services ${ }^{[3,5-8]}$. The focus of this study was on health care within the Canadian province of Manitoba. The Manitoba health system (MHS) has computerized its operations to achieve effective collaboration, teamwork, and effective health information sharing among healthcare providers ${ }^{[9]}$. The MHS has implemented HICT solutions to expedite referral process in the province of Manitoba ${ }^{[10]}$. In this quantitative correlational study, the researchers studied the impact of the high-quality and userfriendly HICT on (1) referral wait times, (2) health information sharing effectiveness, (3) physicians' satisfaction, and (4) patients' satisfaction in the province of Manitoba. In this study, the term high-quality is used to mean fit for purpose, bug-free, and reliable systems; the term user-friendly refers to a system easy to work with.

\section{Research questions}

- $\quad$ RQ1: Is the use of high-quality and user-friendly ICT associated with referral wait time?

- $\quad$ RQ2: Is the use of high-quality and user-friendly ICT associated with health information sharing effectiveness?

- $\quad$ RQ3: Is the use of high-quality and user-friendly ICT associated with physicians’ satisfaction?

- $\quad$ RQ4: Is the use of high-quality and user-friendly ICT associated with patients’ satisfaction?

\section{Subjects and methods and ethical consideration}

The opportunity to participate in this research study was open to all patients, Primary Care Providers (PCPs), and specialist physicians (specialists) who met the criteria. With regard to PCPs and specialists, participants needed to be practicing in the Province of Manitoba. Patients needed to be 18 years of age or older and also needed to be under medical treatment and/or supervision of a specialist physician from April 11, 2011 to July 25, 2011 to be eligible to participate in the survey. Stratified random sampling was used in the study to examine the characteristics of the following population subgroups: (1) specialists, (2) PCPs, and (3) patients.

Sample Size Calculator ${ }^{[11]}$ was used to determine the samples sizes of each subgroup. Using a confidence interval of 15 and the confidence level of $95 \%$, this study proposed to survey 41 PCPs from a population of $1,276^{[12]}$, 41 specialists from a population of $1,216^{[12]}$, and 43 patients from a population size that was not known.

Two hundred specialists were randomly selected from the list provided by the College of Physicians and Surgeons of Manitoba (CPSM) ${ }^{[12]}$. Electronic survey was sent to 100 specialists. Paper survey was sent to 100 specialists. Those who receive paper survey were also given the option to use an electronic survey. A link to the electronic survey was provided in the invitation. The return rate on mailed survey was $44 \%$. The return rate on electronic mail was $10 \%$. The response rate for the specialists' survey was $27 \%$. The receipt of completed surveys exceeded the proposed requirement for the study and allowed the researchers to draw inferences about the specialist physicians’ population.

Two hundred PCPs were randomly selected from the list provided by the CPSM. Fifty PCPs were sent electronic survey and invitations to participate in the study. 150 PCPs were sent paper survey. Those who receive paper survey were also given the option to use an electronic survey. A link to the electronic survey was provided in the invitation. The return rate on mailed survey was $29.3 \%$. The return rate on electronic survey was $18 \%$. Response rate on PCPs' survey was $26.5 \%$. The receipt of completed surveys exceeded the proposed requirement for the present study and allowed the researchers to draw inferences about the PCPs' population. 
To ensure that patients' data were collected from patients seen by specialists during data collection period, 100 letters of invitation and paper survey were sent to randomly selected specialists. The researchers randomly handed additional invitations to 100 patients as they were entering or leaving specialist physicians' offices located at Medical Arts Building at 233 Kennedy Street in Winnipeg, Manitoba. Thirty-seven patients completed the survey while they were waiting to be seen by their specialists. Twenty-four patients used stamped pre-addressed envelopes to return their completed paper survey. The response rate on the patient survey was 30.5\%. The receipt of completed surveys exceeded the proposed requirement for the present study and allowed the researchers to draw inferences about the patients' population.

\subsection{Study instrument}

An extensive search of the literature did not uncover a survey that could be suitable for this study. A survey administered to nine doctoral learners at the University of Phoenix was modified to suit the needs of this study. The original survey was reviewed by nine doctoral learners for face and content validity. Two of these doctoral learners worked in the healthcare industry.

A pilot study helped ensure that participants understood instructions, the survey questions were not confusing, and both paper and online surveys could be completed within the estimated time. Five healthcare professionals and five individuals working in industries other than health care participated in the pilot study. The pilot study participants demonstrated a good understanding of the survey instructions as they answered all questions without difficulty. Participants were able to complete the survey in less than seven minutes which was less than the estimated ten minutes.

\subsection{Data analysis}

The analysis of research questions consisted of correlation analysis, regression analysis, and hypotheses testing. Spearman Rank-Order correlation coefficient (Spearman's rho) and Pearson coefficient were both computed in the study to examine the correlation between the use of ICT and the following variables: (1) referral wait times, (2) health information sharing, (3) physician satisfaction, and (4) patient satisfaction.

Descriptive and inferential statistics were used in the study. The relationship between the use of ICT and other four variables was studied by computing the correlation coefficient and by using regression analysis. The correlation coefficient is a descriptive statistic that describes the linear relationship between two variables ${ }^{[13]}$. Regression analysis was used to further our insight into the relationship between variables. Inferential statistics were used to analyze research questions.

Ordinal variables used in this study were coded as consecutive integers from 1 to 5. Pearson correlation coefficient (Pearson coefficient) is appropriate for use with continual and interval level data. Analyzing ordinal data with Pearson coefficient was not recommended as the violation of the linear regression model by ordinal dependent variables could lead to incorrect conclusions ${ }^{[14]}$. Spearman Rank-Order correlation coefficient was technically appropriate. Spearman's rho and Pearson coefficient were both computed in the study to examine the correlation between the use of ICT and the following variables: (1) referral wait times, (2) health information sharing, (3) physician satisfaction, and (4) patient satisfaction.

The regression model generally helps evaluate the magnitude of change in one variable due to a certain change in another variable $^{[15]}$. Two methods were used to conduct regression analysis: ordinary least squares and ordinal regression model, ordered logit. As Ordinal scales were used in this study to rate various characteristics, doing linear regression was not recommended because of heteroskedastic errors ${ }^{[14]}$. However, a linear regression was used in this study to support the results of the ordinal regression model. Although ordered probit was suitable for ordinal scales, ordered logit was the preferred method because it is easy to compute the odds ratios, which help interpret the substantive effect of the variable. STATA software was used to compute ordered logit and linear regression. 
"Null hypothesis in hypothesis testing for a correlation is usually that in the population the true relation between the two variables is no correlation" ${ }^{[13]}$. Two methods were used in this study to test null hypotheses. First, the correlation coefficient, Spearman's rho computed in descriptive statistics, was used to test the null hypotheses. Second, a $t$ test was used at an n-2 degrees of freedom and 95\% confidence level to determine whether two variables were correlated in a significant way. The rationale for using two methods to test hypotheses was to ensure that they both result in the same decision, which is the rejection or the acceptance of the null hypothesis. The internal consistency reliability coefficients (Cronbach’ alpha) for the scales used in this study are well above the level of 0.7, acceptable for the analysis purpose.

\section{Findings}

Majority of specialists and PCPs who participated in the study were in age range 50-60. Whereas, the majority of patients were 30 years old or younger. Descriptive statistics of participants' age range is shown in Table 1. Majority of physicians (92.45\% of specialists and $73.58 \%$ of PCPs) practice in urban areas. $79.25 \%$ of patients who participated in the study live in urban areas; while only $20.75 \%$ live in rural location. Table 2 shows the participants demographics.

Table 1. Descriptive statistics participants age range $(\mathrm{N}=159)$

\begin{tabular}{llll}
\hline Age Range & Specialist & PCP & Patients \\
\hline Less than 30 & 0.0 & 7.55 & 28.30 \\
$31-40$ & 18.87 & 24.53 & 22.64 \\
$41-50$ & 16.98 & 26.42 & 24.53 \\
$51-60$ & 41.51 & 37.74 & 11.32 \\
Greater than 60 & 22.64 & 3.77 & 13.21 \\
Total & 100 & 100 & 100 \\
\hline
\end{tabular}

Table 2. Participants demographics $(\mathrm{N}=159)$

\begin{tabular}{lll}
\hline & n & Percent (\%) \\
\hline Participants by Stratum & & \\
Specialist physicians & 53 & 33.33 \\
Primary care physicians & 53 & 33.33 \\
Patients & 53 & 33.33 \\
Participants Location & & \\
Specialists Urban & 49 & 92.45 \\
Specialists Rural & 4 & 7.55 \\
PCPs Urban & 39 & 73.58 \\
PCPs Rural & 14 & 26.42 \\
Patients Urban & 42 & 79.25 \\
Patients Rural & 11 & 20.75 \\
\hline
\end{tabular}

\subsection{RQ1: Is the use of high-quality and user-friendly ICT associated with referral wait time?}

A correlation coefficient was used to test the null hypothesis $\left(\mathrm{H}_{1}\right)$. A correlation coefficient that is very close to zero means an absence of correlation. Spearman's rho of 0.095, shown in Table 3, suggested the absence of relationship between the use of ICT and referral wait time in the MHS. There was not enough evidence to reject the null hypothesis.

$\mathrm{H} 1_{0}$ was also tested with $t$-test at a significant level of 0.05 . Using 157 degree of freedom and 0.05 probability level, Statistics Calculator provided by Soper ${ }^{[16]}$ generated $t$-value (two-tailed): \pm 1.97518917 . Since $p$-value (.23) was greater than 0.05 and that the statistic value $t=1.2 \mathrm{did}$ not fall in the rejection region, there was not enough evidence to reject $\mathrm{H}_{0}$. 
The result of the ordered logit mirrored the results of the correlation analysis. Ordered logit results suggested that the use of ICT was not significantly associated with wait time. One unit increase in the use of ICT is expected to lead to 0.067 units increase in wait time.

Table 3. Research question one

\begin{tabular}{|c|c|c|c|c|c|c|c|c|c|c|c|c|}
\hline \multicolumn{13}{|c|}{ Spearman' rho and Pearson coefficients } \\
\hline \multirow{2}{*}{\multicolumn{3}{|c|}{$\begin{array}{l}\text { Health Outcome Variable } \\
\text { Wait Time }\end{array}$}} & \multirow{2}{*}{\multicolumn{5}{|c|}{$\begin{array}{l}\text { Spearman Correlation with Use of ICT ( } p \text {-value) } \\
0.095(0.23) t=1.2\end{array}$}} & \multirow{2}{*}{\multicolumn{5}{|c|}{$\begin{array}{l}\text { Pearson Correlation with use of ICT ( } p \text {-value) } \\
0.06(0.47) t=0.73\end{array}$}} \\
\hline & & & & & & & & & & & & \\
\hline \multicolumn{13}{|c|}{ Ordered Logit Results } \\
\hline & $\begin{array}{l}\text { ICT } \\
\text { coef. }\end{array}$ & $\begin{array}{l}\text { ICT s } \\
\text { error }\end{array}$ & & $\begin{array}{l}\text { ICT } \\
p \text {-value }\end{array}$ & $\begin{array}{l}\text { ICT odds } \\
\text { ratio }\end{array}$ & $\begin{array}{l}\text { Cut } \\
\text { point } 1\end{array}$ & $\begin{array}{l}\text { Cut } \\
\text { point } 2\end{array}$ & $\begin{array}{l}\text { Cut } \\
\text { point } 3\end{array}$ & $\begin{array}{l}\text { Cut } \\
\text { point } 4\end{array}$ & $\mathrm{n}$ & $\begin{array}{l}\text { LR } \\
\text { Chi2 }\end{array}$ & $\begin{array}{l}\text { LR Chi2 } \\
p \text {-value }\end{array}$ \\
\hline Wait Time & 0.067 & 0.099 & & 0.503 & 1.069 & -3.79 & -1.96 & -0.48 & 0.91 & 159 & 0.45 & 0.50 \\
\hline \multicolumn{13}{|c|}{ Linear Regression Results } \\
\hline & \multicolumn{3}{|c|}{$\begin{array}{l}\text { ICT } \\
\text { coefficient }\end{array}$} & $\begin{array}{l}\text { ICT std. } \\
\text { error }\end{array}$ & $\begin{array}{l}\text { ICT } \\
p \text {-value }\end{array}$ & \multicolumn{2}{|c|}{ Constant } & $\begin{array}{l}\text { Constant } \\
\text { std. error }\end{array}$ & \multicolumn{2}{|c|}{$\begin{array}{l}\text { Constant } \\
p \text {-value }\end{array}$} & R-square & $\mathrm{n}$ \\
\hline Wait Time & \multicolumn{3}{|c|}{0.042} & 0.054 & 0.442 & \multicolumn{2}{|c|}{3.750} & 0.156 & 0.00 & & 0.00 & 159 \\
\hline
\end{tabular}

The results of the linear regression supported those of the ordered logit. The linear regression results mirrored the correlation analysis. The size of the coefficient indicated the expected change in one variable, for a one unit change in another variable. One unit increase in the use of ICT is expected to lead to 0.042 units increase in wait time. The $r$-square statistic tells the proportion of variance in one variable, explained by another variable. The use of ICT explains $0 \%$ of the variance in wait time. The results can be found in Table 3.

\section{RQ1 null hypothesis testing}

A correlation coefficient was used to test $\mathrm{H}_{0}$. It suggested the absence of relationship between the use of ICT and referral wait time in the MHS, leading to the acceptance of the null hypothesis. The use of ICT and wait time scores are shown in Figure 1.

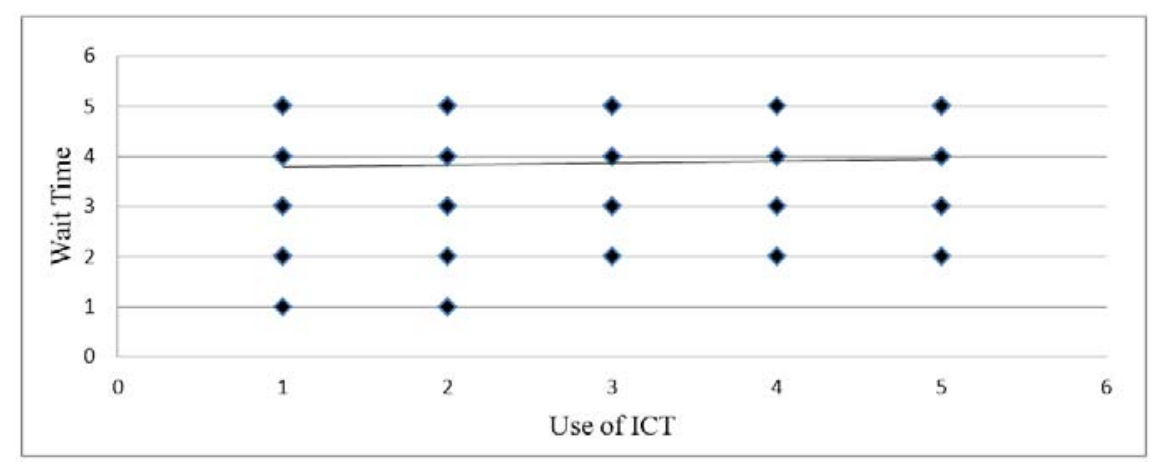

Figure 1. Correlational graph of the use of ICT and wait time

\subsection{RQ2: Is the use of high-quality and user-friendly ICT associated with health information sharing effectiveness?}

A correlation coefficient was used to test the null hypothesis $\left(\mathrm{H} 2_{0}\right)$. Spearman rho of 0.23 shown in Table 4 suggested a weak correlation between the use of ICT in the MHS and health information sharing among physicians. As 0.05 is the usual $p$-value threshold for statistical significance, health information sharing is statistically significant, though the correlation is not very strong. This led to the rejection of $\mathrm{H}_{2}$ and the acceptance of the alternative hypothesis $\left(\mathrm{H} 2_{1}\right)$.

$\mathrm{H} 2_{0}$ was also tested with $t$-test at a significant level of 0.05 . Using 104 degree of freedom and 0.05 probability level, Statistics Calculator provided by Soper ${ }^{[16]}$ generated $t$-value (two-tailed): \pm 1.98303752 . Since the $p$-value (.02) is less 
than 0.05 and that the statistic value $t=2.41$ was inside the rejection region, $\mathrm{H} 2_{0}$ was rejected. At the 0.05 level, there was a significant correlation between the use of ICT and health information sharing effectiveness.

Table 4. Research question two

\begin{tabular}{|c|c|c|c|c|c|c|c|c|c|c|c|c|c|c|}
\hline \multicolumn{15}{|c|}{ Spearman' rho and Pearson coefficients } \\
\hline \multirow{2}{*}{\multicolumn{3}{|c|}{$\begin{array}{l}\text { Health Outcome Variable } \\
\text { Health Info Sharing }\end{array}$}} & \multicolumn{5}{|c|}{ Spearman Correlation with Use of ICT ( $p$-value) } & \multicolumn{7}{|c|}{ Pearson Correlation with use of ICT ( $p$-value) } \\
\hline & & & \multicolumn{5}{|c|}{$0.23(0.02) t=2.41$} & \multicolumn{7}{|c|}{$0.24(0.01) t=2.52$} \\
\hline \multicolumn{15}{|c|}{ Ordered Logit Results } \\
\hline & $\begin{array}{l}\text { ICT } \\
\text { coef. }\end{array}$ & $\begin{array}{l}\text { ICT } \\
\text { errol }\end{array}$ & & $\begin{array}{l}\text { ICT } \\
p \text {-value }\end{array}$ & $\begin{array}{l}\text { ICT odds } \\
\text { ratio }\end{array}$ & $\begin{array}{l}\text { Cut } \\
\text { point } 1\end{array}$ & $\begin{array}{l}\text { Cut } \\
\text { point } 2\end{array}$ & $\begin{array}{l}\text { Cut } \\
\text { point } 3\end{array}$ & $\begin{array}{l}\text { Cut } \\
\text { point } 4\end{array}$ & $\mathrm{n}$ & & & $\begin{array}{l}\text { LR } \\
p \text {-val }\end{array}$ & $\begin{array}{l}\text { Chi2 } \\
\text { lue }\end{array}$ \\
\hline $\begin{array}{l}\text { Health Info } \\
\text { Sharing }\end{array}$ & 0.588 & 0.19 & & 0.00 & 1.799 & 0.488 & 2.549 & 3.325 & 3.660 & 106 & & 84 & 0.03 & \\
\hline \multicolumn{15}{|c|}{ Linear Regression Results } \\
\hline & & & & $\begin{array}{l}\text { CT } \\
\text { coefficient }\end{array}$ & $\begin{array}{l}\text { ICT stc } \\
\text { error }\end{array}$ & $\begin{array}{l}\text { ICT } \\
p \text {-value }\end{array}$ & Constant & \multicolumn{2}{|c|}{$\begin{array}{l}\text { Constant std. } \\
\text { error }\end{array}$} & $\begin{array}{l}\text { Const } \\
p \text {-valu }\end{array}$ & \multicolumn{3}{|c|}{ R-square } & $\mathrm{n}$ \\
\hline \multicolumn{3}{|c|}{ Health Information Sharing } & & .163 & 0.069 & 0.019 & 3.704 & 0.2 & & 0.02 & & 0.06 & & 106 \\
\hline
\end{tabular}

The results of the ordered logit mirrored the results of the correlation analysis. Ordered logit results suggested that the use of ICT was significantly associated with health information sharing. One unit increase in the use of ICT is expected to lead to 0.588 units increase in health information sharing.

The results of the linear regression supported those of the ordered logit. The linear regression results mirrored the correlation analysis. One unit increase in the use of ICT was expected to lead to 0.163 units increase in health information sharing. The use of ICT explains $6 \%$ of the variance in health information sharing. The use of ICT and health information sharing data are shown in Table 4.

\section{RQ2 Null hypothesis testing}

A correlation coefficient was used to test $\mathrm{H}_{2}$. It suggested a weak correlation between the use of ICT in the MHS and health information sharing among physicians. As 0.05 is the usual $p$-value threshold for statistical significance, health information sharing is statistically significant, though the correlation is not very strong. This led to the rejection of $\mathrm{H} 2_{0}$ and the acceptance of $\mathrm{H}_{1}$. The use of ICT and health information sharing effectiveness scores are shown in Figure 2.

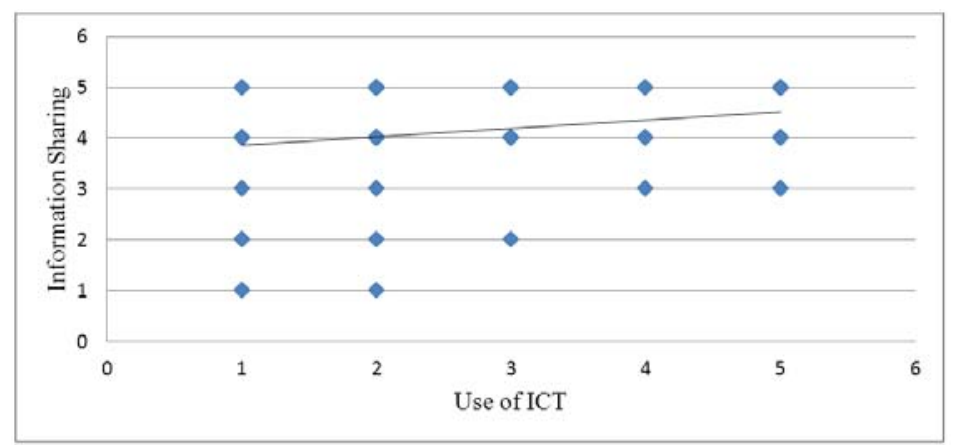

Figure 2. Correlational graph of the use of ICT and information sharing

\subsection{RQ3: Is the use of high-quality and user-friendly ICT associated with physicians' satisfaction?}

A correlation coefficient was used to test the null hypothesis $\left(\mathrm{H}_{3}\right)$. Spearman rho of 0.26 shown in Table 5 suggested a weak correlation between the use of ICT and the physician satisfaction in the MHS. As 0.05 is the usual $p$-value threshold for statistical significance, physicians' satisfaction is statistically significant, though the correlation is not very strong. This led to the rejection of $\mathrm{H}_{0}$ and the acceptance of the alternative hypothesis $\left(\mathrm{H}_{1}\right)$. 
Table 5. Research question three

\begin{tabular}{|c|c|c|c|c|c|c|c|c|c|c|c|c|c|}
\hline \multicolumn{14}{|c|}{ Spearman' rho and Pearson coefficients } \\
\hline \multirow{2}{*}{\multicolumn{2}{|c|}{$\begin{array}{l}\text { Health Outcome Variable } \\
\text { Physician Satisfaction }\end{array}$}} & \multicolumn{7}{|c|}{ Spearman Correlation with Use of ICT ( $p$-value) } & \multicolumn{5}{|c|}{ Pearson Correlation with use of ICT ( $p$-value) } \\
\hline & & \multicolumn{7}{|c|}{$0.26(0.01) t=2.75$} & \multicolumn{5}{|c|}{$0.28(0.00) t=2.97$} \\
\hline \multicolumn{14}{|c|}{ Ordered Logit Results } \\
\hline & $\begin{array}{l}\text { ICT } \\
\text { coef. }\end{array}$ & $\begin{array}{l}\text { ICT std. } \\
\text { error }\end{array}$ & $\begin{array}{l}\text { ICT } \\
p \text {-va }\end{array}$ & & $\begin{array}{l}\text { ICT } \\
\text { ratio }\end{array}$ & odds & $\begin{array}{l}\text { Cut } \\
\text { point } 1\end{array}$ & $\begin{array}{l}\text { Cut } \\
\text { point } 2\end{array}$ & $\begin{array}{l}\text { Cut } \\
\text { point } 3\end{array}$ & $\begin{array}{l}\text { Cut } \\
\text { point } 4\end{array}$ & $\mathrm{n}$ & $\begin{array}{l}\text { LR } \\
\text { Chi2 }\end{array}$ & $\begin{array}{l}\text { LR Chi2 } \\
p \text {-value }\end{array}$ \\
\hline $\begin{array}{l}\text { Physician } \\
\text { Satisfaction }\end{array}$ & 0.591 & 0.191 & 0.00 & & 1.807 & & 0.124 & 2.173 & 2.968 & 3.3105 & 106 & 9.79 & 0.00 \\
\hline \multicolumn{14}{|c|}{ Linear Regression Results } \\
\hline & & \multicolumn{2}{|c|}{$\begin{array}{l}\text { ICT } \\
\text { coefficient }\end{array}$} & \multicolumn{2}{|c|}{$\begin{array}{l}\text { ICT std. } \\
\text { error }\end{array}$} & \multicolumn{2}{|c|}{$\begin{array}{l}\text { ICT } \\
p \text {-value }\end{array}$} & nstant & $\begin{array}{l}\text { Constant } \\
\text { std. error }\end{array}$ & \multicolumn{2}{|c|}{$\begin{array}{l}\text { Constant } \\
p \text {-value }\end{array}$} & R-square & $\mathrm{n}$ \\
\hline \multicolumn{2}{|c|}{ Physician Satisfaction } & \multicolumn{2}{|c|}{0.190} & \multicolumn{2}{|c|}{0.064} & \multicolumn{2}{|c|}{0.004} & 20 & 0.213 & \multicolumn{2}{|l|}{0.00} & 0.08 & 106 \\
\hline
\end{tabular}

$\mathrm{H}_{3}$ was also tested with $t$-test at a significant level of 0.05 . Using 104 degree of freedom and 0.05 probability level, Statistics Calculator provided by Soper ${ }^{[16]}$ generated $t$-value (two-tailed): \pm 1.98303752 . Since $p$-value (.01) was less than 0.05 and that the statistic value $t=2.75$ was inside the rejection region, $\mathrm{H}_{0}{ }_{0}$ was rejected. At the 0.05 level, there was a significant correlation between the use of ICT and physicians' satisfaction.

The results of the ordered logit mirrored the results of the correlation analysis. Ordered logit results suggested that the use of ICT was significantly associated with physicians' satisfaction. One unit increase in the use of ICT is expected to lead to 0.591 units increase in physicians’ satisfaction.

The results of the linear regression supported those of the ordered logit. The linear regression results mirrored the correlation analysis. One unit increase in the use of ICT is expected to lead to 0.190 units increase in physicians' satisfaction. The use of ICT explains $8 \%$ of the variance in physicians' satisfaction. The use of ICT and physicians' satisfaction scores are shown in Table 5.

\section{RQ3 null hypothesis testing}

A correlation coefficient was used to test $\mathrm{H}_{0}$. It suggested a weak correlation between the use of ICT and the physicians' satisfaction in the MHS. As 0.05 is the usual p-value threshold for statistical significance, physicians' satisfaction is statistically significant, though the correlation is not very strong. This led to the rejection of $\mathrm{H} 3_{0}$ and the acceptance of $\mathrm{H} 3_{1}$. The use of ICT and physicians' satisfaction scores are shown in Figure 3.

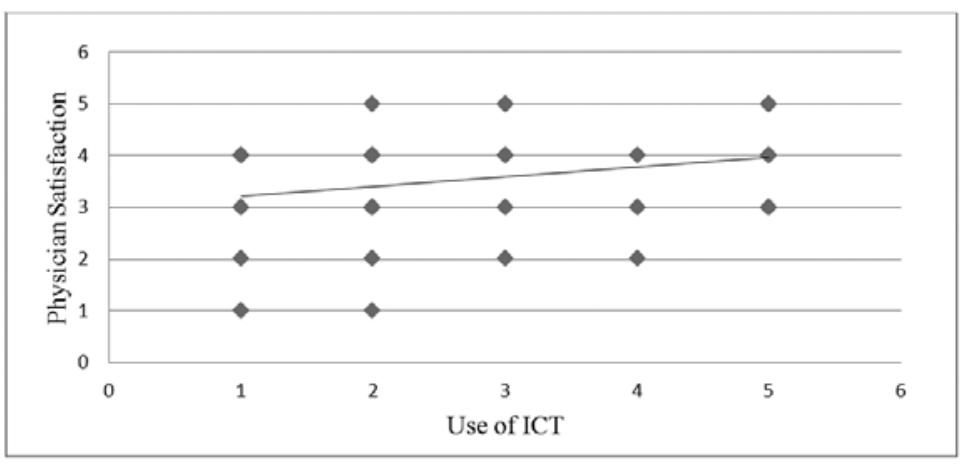

Figure 3. Correlational graph of the use of ICT and physician satisfaction

\subsection{RQ4: I s the use of high-quality and user-friendly ICT associated with patients' satisfaction?}

A correlation coefficient was used to test the null hypothesis $\left(\mathrm{H} 4_{0}\right)$. Spearman rho, 0.38 , shown in Table 6 suggests a moderate correlation between the use of ICT and patients' satisfaction in the MHS. As 0.05 is the usual $p$-value threshold 
for statistical significance, patients' satisfaction is statistically significant, though the correlations are not very strong. This led to the rejection of $\mathrm{H}_{0}$ and the acceptance of the alternative hypothesis $\left(\mathrm{H} 4_{1}\right)$.

Table 6. Research question four

\begin{tabular}{|c|c|c|c|c|c|c|c|c|c|c|}
\hline \multicolumn{11}{|c|}{ Spearman's rho and Pearson coefficients } \\
\hline \multirow{2}{*}{\multicolumn{2}{|c|}{$\begin{array}{l}\text { Health Outcome Variable } \\
\text { Patient Satisfaction }\end{array}$}} & \multicolumn{4}{|c|}{ Spearman Correlation with Use of ICT ( $p$-value) } & \multicolumn{5}{|c|}{ Pearson Correlation with use of ICT ( $p$-value) } \\
\hline & & \multicolumn{4}{|c|}{$0.38(0.01) t=2.93$} & \multicolumn{5}{|c|}{$0.35(0.01) t=2.67$} \\
\hline \multicolumn{11}{|l|}{ Ordered Logit Results } \\
\hline & $\begin{array}{l}\text { ICT } \\
\text { coef. }\end{array}$ & $\begin{array}{l}\text { ICT std. } \\
\text { error }\end{array}$ & $\begin{array}{l}\text { ICT } \\
p \text {-value }\end{array}$ & $\begin{array}{l}\text { ICT odds } \\
\text { ratio }\end{array}$ & $\begin{array}{l}\text { Cut } \\
\text { point } 1\end{array}$ & $\begin{array}{l}\text { Cut } \\
\text { point } 2\end{array}$ & $\begin{array}{l}\text { Cut } \\
\text { point } 3\end{array}$ & $\mathrm{n}$ & $\begin{array}{l}\text { LR } \\
\text { Chi2 }\end{array}$ & $\begin{array}{l}\text { LR Chi2 } \\
p \text {-value }\end{array}$ \\
\hline Patient Satisfaction & 1.535 & .616 & 0.013 & 4.643 & 7.799 & 9.187 & 10.388 & 53 & 8.93 & 0.00 \\
\hline \multicolumn{11}{|c|}{ Linear Regression Results } \\
\hline & \multicolumn{2}{|c|}{$\begin{array}{l}\text { ICT } \\
\text { coefficient }\end{array}$} & $\begin{array}{l}\text { ICT std. } \\
\text { error }\end{array}$ & ICT $p$-value & Constant & \multicolumn{2}{|c|}{$\begin{array}{l}\text { Constant } \\
\text { std. error }\end{array}$} & $\begin{array}{l}\text { Constant } \\
p \text {-value }\end{array}$ & \multicolumn{2}{|c|}{ R-square } \\
\hline Patient Satisfaction & \multicolumn{2}{|c|}{0.564} & 0.133 & 0.00 & 2.978 & \multicolumn{2}{|c|}{0.133} & 0.00 & \multicolumn{2}{|l|}{0.12} \\
\hline
\end{tabular}

$\mathrm{H} 4_{0}$ was also tested with $t$-test at a significant level of 0.05 . Using 51 degree of freedom and 0.05 probability level, Statistics Calculator provided by Soper ${ }^{[16]}$, generated $t$-value (two-tailed): \pm 2.00758377 . Since the $p$-value (.01) was less than 0.05 and that the statistic value $t=2.93$ was inside the rejection region, $\mathrm{H} 4_{0}$ was rejected. At the 0.05 level, there was a significant correlation between the use of ICT and patients' satisfaction.

The results of the ordered logit mirrored the results of the correlation analysis. Ordered logit results suggested that the use of ICT was significantly associated with patients' satisfaction. One unit increase in the use of ICT is expected to lead to 1.535 units increase in patients' satisfaction.

The results of the linear regression supported those of ordered the logit. The linear regression results mirrored the correlation analysis. One unit increase in the use of ICT is expected to lead to 0.564 units increase in patients' satisfaction. The use of ICT explains 12\% of the variance in patients' satisfaction. The use of ICT and patients' satisfaction scores are shown in Table 6.

\section{RQ4 null hypothesis testing}

A correlation coefficient was used to test $\mathrm{H}_{4}$. It suggested a moderate correlation between the use of ICT and patient satisfaction in the MHS. As 0.05 is the usual $p$-value threshold for statistical significance, patient satisfaction is statistically significant, though the correlation is not very strong. This led to the rejection of $\mathrm{H} 4_{0}$ and the acceptance of $\mathrm{H} 4_{1}$. A collection of use of ICT and patients' satisfaction scores is provided as shown in Figure 4.

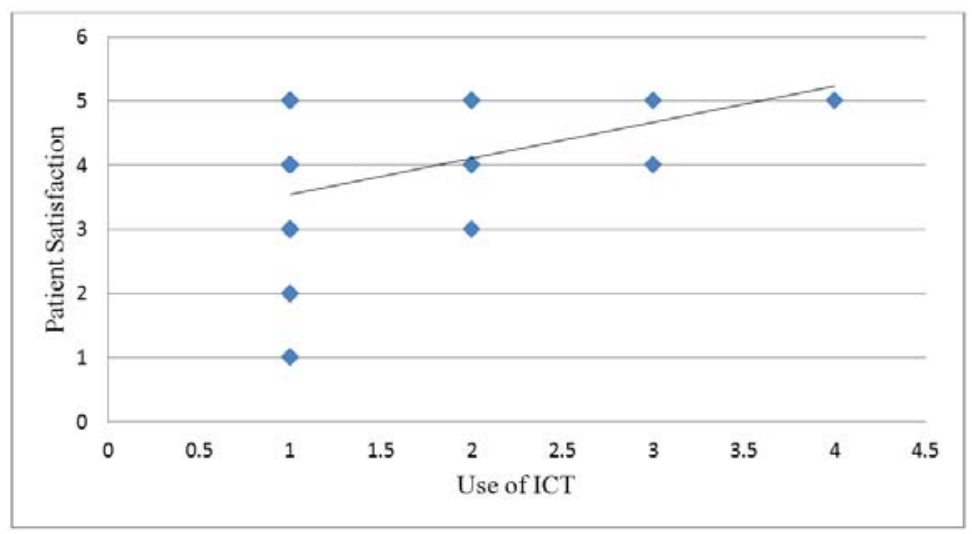

Figure 4. Correlational graph of the use of ICT and patient satisfaction 


\section{Discussion}

Despite ICT investments to address wait times for medical services in the MHS, this study revealed that Manitobans did not appear to be satisfied with referral wait times. The absence of a significant correlation between ICT use and wait times could be due to the kind of ICT systems used in the MHS and its inability to address the root cause of long delays for medical services in Manitoba. The performance effect of ICT systems designed to automate paper-based processes, for instance, is less significant than the impact of the systems that transform entire processes ${ }^{[17]}$. Organizational culture plays a crucial role in the impact of ICT on the performance of healthcare organizations ${ }^{[18]}$. The lack of a significant association between ICT use and wait times in the MHS, may suggest that wait times in Manitoba are symptoms of organizational structure and culture.

Most participants believed in the potential of ICT to improve healthcare delivery in the Manitoba health system. However, data analysis revealed that less than $40 \%$ of participants' proficiency with ICT was above average. This has an implication on physicians' frequency to use ICT to manage health information. As a result, ICT investments in the MHS have not improved healthcare delivery in Manitoba. Manitoba health leaders should invest in ICT capabilities to gain the most effective use from ICT investments. It is imperative to invest in ICT capabilities instead of injecting ICT resources into the assortment of the MHS with the hopes of bettering bottom-line performance. Physicians and patients' proficiency with modern health ICT systems and their willingness to adopt modern ICT systems are critical to the MHS capacity to exploit ICT successfully.

Data analysis indicated a slow adoption of ICT systems in the Manitoba health system. This study did not reveal that respondents' age or location was a factor in the adoption of ICT. The lack of fit between ICT systems and the work practices, ICT systems and the work environment, and ICT systems and the culture they are expected to support could be some of the root causes of slow adoption of ICT systems in the MHS ${ }^{[19]}$. Also, the lack of healthcare providers' input in the ICT systems design could result in the implementation of systems that are not user-friendly. The lack of userfriendliness of HICT has bearing on the adoption of health ICT in Manitoba.

The technological innovation approach to address wait times in the MHS means a transformation of practice. The exploitation of change through innovation is done through the work of teams embedded in the organizations ${ }^{[20]}$. It is critical to understand that the success of change implementation through innovation depends on the degree to which healthcare providers embrace the vision of their leaders. The development of strategies to improve healthcare delivery through technological innovation in the MHS requires effective transformational leadership to help overcome healthcare providers' resistance.

\section{Study limitation}

Various limitations may have existed in this study, and among these limitations, would be (1) sample size, (2) validity, (3) reliability, (4) response rate, and (5) truthfulness of respondents. The current study was confined to surveying physicians practicing in the province of Manitoba, in Canada, and patients, consumers of specialists' care. The purpose of the study was to determine relationships among variables. There was no manipulation of data.

Efforts were made to ensure that data collection instrument used in the study allowed for the capturing of data it was intended to gather. Response rates on all three strata exceeded the proposed requirement for the confidence level of $95 \%$ needed to draw inferences about the population being studied. It was assumed that participants responded truthfully as participants' responses did not significantly deviate from the mean.

\section{Conclusion and implication}

The results of this study may provide MHS leaders, decision makers, and policy makers with more information relating to the association between ICT use and the following variables: (1) referral wait times, (2) health information sharing, 
(3) physicians' satisfaction, and (4) patients' satisfaction. A weak correlation was observed between the use of ICT and health information sharing and between the use of ICT and physicians' satisfaction. A moderate correlation was observed between the use of ICT and patients' satisfaction. No significant relationship was observed between the use of ICT and referral wait times.

From the discoveries of this study, the realization is that ICT has not transformed the MHS the same way it has transformed other countries health systems and other Canadian industries. This study results brought forth physicians' slow adoption of health ICT. As a result, ICT investments have not improved healthcare delivery in the MHS. ICT alone cannot improve healthcare delivery in the Manitoba health system was a revelation of the study. When developing strategies to improve healthcare delivery in the MHS, Manitoba health leaders should implement an integrated approach that includes meeting the needs of patients, adopting effective ICT systems, implementing mixed health system, and allowing medical outsourcing.

\subsection{Recommendations to healthcare leaders and educators}

\subsubsection{Meet the needs of patients to improve their satisfaction}

It is critical to use patients' satisfaction as an indicator of the quality of healthcare delivery. Patients' satisfaction is a crucial measure of patients' feeling about their interaction with the healthcare system ${ }^{[21]}$. Understanding patients' satisfaction is essential in developing effective approaches to enhance the quality of care and health outcomes. It is important to implement strategies that place patients at the center of the healthcare system by meeting the needs of patients. This requires (1) increasing the supply of competent physicians, (2) allowing physicians to spend necessary time with their patients, and (3) empowering patients to have access to information needed to make informed decisions about their care. Effective use of ICT can help meet these last two requirements and improve patient satisfaction with the system. With regard to the supply of competent physicians, it is imperative to partner with medical schools in the province to develop a curriculum that meets the twenty-first century health care requirements. These requirements include among others physicians' ICT skills, medical skills, interpersonal skills, and referral best practices. This recommendation has the potential to better physician-patient communication and improve the referral process, and results in improved patient satisfaction.

\subsubsection{Adopt effective ICT systems to improve health information sharing and physician's satisfaction}

Upon graduation, most young PCPs work in silos in private practices and lack the support of experienced colleagues ${ }^{[4]}$. They often refer patients to specialists as a way to seek a second opinion. These unnecessary referrals result in longer waiting times for patients and longer waiting list for specialists. Modern ICT allows the capture of health information, knowledge, and expertise for further use ${ }^{[22]}$. Effective use of ICT results in better information sharing among healthcare providers. It improves physicians' satisfaction with their practice as they can have access to the support of virtual colleagues at any time. It is therefore critical to ensure that an effective health knowledge repository component is integrated into HICT systems in support of wait time management to minimize unnecessary referrals. Also, the implementtation of an expert system is required to allow primary care providers to access specialists' expertise at a distance and reduce unnecessary referrals. Successful implementation and adoption of these two ICT systems have the potential to improve physicians' satisfaction with their practice.

\subsubsection{I mplement mixed health system to reduce referral wait times}

It is crucial that federal and provincial governments examine the impacts of a mixed health system on healthcare delivery. The coexistence of public and private health systems operating under the supervision of the provincial government could shorten wait times in Manitoba. The success of a mixed health system in Manitoba would depend on effective internal partnership in the MHS. It is critical to implement a system where public healthcare providers, public insurers, private healthcare providers, private insurers, and patients are viewed as partners. Those who lead the MHS should be responsible 
for (1) supervising the healthcare system, (2) defining the general orientation of health policy, and (3) developing a service level agreement. Lessons learned from the current fee-for-service business model and the private employer-sponsored insurance can help those who lead the MHS implement a mixed health system. The success of such mixed system relies on the effectiveness of ICT systems. This recommendation has the potential to reduce wait times experienced in publiclyfunded health system and result in patients’ satisfaction.

\subsubsection{Allow medical outsourcing to improve patients and physician's satisfaction}

It is imperative that federal and provincial governments understand the current environment in which the MHS is operating. External partnerships, such as in-sourcing, outsourcing, and off-shoring, have become a way of life for successful organizations in this global economy ${ }^{[23]}$. The shortage of healthcare providers, especially in high-demand specialties, in Manitoba and the ICT inability to revolutionize the MHS have reduced the MHS capability to meet the increasing health needs of Manitoban residents. Manitoba health leaders should consider building strategic and trusted partnerships with foreign medical services providers. The portability of the Canadian Medicare should be enhanced to allow Manitobans in particular and Canadians in general to seek medical services abroad. The success of the proposed external partnership will depend on two factors. The first factor consists of developing a service level agreement system to determine specific medical services and performance levels. The second factor consists of implementing effective global ICT systems to interact with medical services providers around the globe. As this recommendation has the potential to achieve balance between supply and demand of health care services, it has the potential to reduce physicians and patients' frustration with the system and result in improved satisfaction with the system.

The recommendation is also to conduct a similar survey using the same instruments in other geographic locations within Canada and outside Canada in order to compare the influence of the use of health information and communication technology on health care delivery and the perception of patients and healthcare providers of its use.

\section{References}

[1] Chaudhry B, WangJ, Wu. S., et al. Systematic review: impact of health information technology on quality, efficiency, and costs of medical care. Ann Intern Med. 2006; 144: 742-752. PMid: 16702590.

http://dx.doi.org/10.7326/0003-4819-144-10-200605160-00125

[2] Munn JD., Wozniak L. Single-payer health care systems: The roles and responsibilities of the public and private sectors. Benefits Quarterly. 2007 Third Quarter; 23(3): 7-16. PMid: 17886729 (AN 26069361).

[3] Kosub D. Canada gets poor grades for healthcare timeliness. Medical Device Daily. 1/12/2010; 14(7): 1-9.

[4] Romanow RJ. Building on Values: The Future of Health Care in Canada - Final Report. 2002. Available from: http://www.hc-sc.gc.ca/hcs-sss/com/fed/romanow/index-eng.php

[5] Canada Health Infoway. EHR advancing Canada’s next generation of healthcare. 2010. Available from: www.infoway-inforoute.ca/Documents/Vision_Summary_EN.pdf

[6] CMAJ. Information technology and health care in Canada: 2007 status report. Canadian Medical Association. 2007. Available from: http://www.cma.ca/multimedia /CMA/Content_Images /Inside_cma/ HIT/ 2007_status_report/IT-handbook-e.pdf

[7] Pooley E. MEDICARE INC. Canadian Business. 2007; 80(20): 160-164,166. Retrieved December 20, 2010, from CBCA Complete. (Document ID: 1371374271).

[8] Rachlis, M. Prescription for Excellence: How Innovation is Saving Canada's Health Care System. HarperCollins Publishers Ltd. 2004.

[9] eHealth (n.d.). Connections in Health Care. June 24, 2010. Available from: http://www.manitoba-ehealth.ca/

[10] Manitoba Health Manitoba Wait Time Information. 2010. Available from: http://www.gov. mb.ca/ health/ wait time/index.html

[11] Sample Size Calculator. 2009. Available from: www.surveysystem.com/sscalc.htm

[12] CPSM. The College of Physicians \& Surgeons of Manitoba. 2010. Available from: http://cpsm.mb.ca/

[13] Aron, A, Aron E N, Coups, E.J. Statistics for Psychology (5th ed.). Upper Saddle River, New Jersey: Pearson Education. 2009. 452.

[14] Long S J, Freese J. Regression Models for Categorical Dependent Variables Using Strata (2nd ed.). College Station, Texas: StrataCorp LP. 2006. 
[15] Mann P S, Lacke. Introductory Statistics. New York, New York: John Wiley \& Sons Inc. 2010.

[16] Soper D S. Statistics Calculators, 2001. Available from: http://danielsoper.com/statcalc3/calc.aspx?id=10

[17] Bhattacherjee A, Hikmet N, Menachemi, N., Kayhan, V.O., Brooks, R.G. The Differential Performance Effects of Healthcare Information Technology Adoption. Information Systems Management. 2007; 24(1): 5-14. http://dx.doi.org/10.1080/10580530601036778

[18] Herbert C L, Yoder LM. Creating the ultimate healing environment: integrating evidence-based design, IT and patient safety. Healthcare Executive. ISSN: 0883-5381. 2008 Sep-Oct; 23(5): 16-8, 20, 22-3.

[19] Avison D., Young, T. Time to rethink health care and ICT? Communications of the ACM. Jun 2007; 50(6): 69-74, 6p.

[20] West MA, Hirst G, Richter A., Shipton H. Twelve steps to heaven: Successfully managing change through developing innovative teams. European Journal of Work \& Organizational Psychology. 2004; 13(2): 269. http://dx.doi.org/10.1080/13594320444000092

[21] Fos P J, Fine D J, Amy BW, Z'uniga MA. Managerial Epidemiology for Health Care Organizations (2nd ed.). San Francisco, California: John Wiley \& Sons, Inc. 2005.

[22] Landry B JL, Mahesh S., Hartman S. The impact of the pervasive information age on healthcare organizations. Journal of Health \& Human Services Administration. 2005; 27(4): 444-464. PMid: 16318014.

[23] McNurlin B C, Sprague R H. Information Systems Management in practice (7th ed.). Upper Saddle River: Pears. 2006. 